\title{
Application of environmetric methods to investigate control factors on water quality
}

\author{
Hülya Boyacioglu ${ }^{1 *}$, Hayal Boyacioglu² \\ ${ }^{1}$ Dokuz Eylul University, Turkey \\ Department of Environmental Engineering \\ ${ }^{2}$ Ege University, Turkey \\ Department of Statistics
}

*Corresponding author's e-mail: hulya.boyacioglu@deu.edu.tr

Keywords: water quality, factor analysis, environmetric methods, discriminant analysis.

\begin{abstract}
In the study, environmetric methods were successfully performed a) to explore natural and anthropogenic controls on reservoir water quality, b) to investigate spatial and temporal differences in quality, and c) to determine quality variables discriminating three reservoirs in Izmir, Turkey. Results showed that overall water quality was mainly governed by "natural factors" in the whole region. A parameter that was the most important in contributing to water quality variation for one reservoir was not important for another. Between summer and winter periods, difference in arsenic concentrations were statistically significant in the Tahtalı, Ürkmez and iron concentrations were in the Balçova reservoirs. Observation of high/low levels in two seasons was explained by different processes as for instance, dilution from runoff at times of high flow seeped through soil and entered the river along with the rainwater run-off and adsorption. Three variables "boron, arsenic and sulphate" discriminated quality among Balçova \& Tahtal, Balçova \& Ürkmez and two variables "zinc and arsenic" among the Tahtalı \& Ürkmez reservoirs. The results illustrated the usefulness of multivariate statistical techniques to fingerprint pollution sources and investigate temporal/spatial variations in water quality.
\end{abstract}

\section{Introduction}

The state of water quality is the result of complex natural and man-made conditions and the consequent interactions in both time and space. Accordingly, abstracting the essence of water quality conditions is often very difficult. The purpose of monitoring is generally laid down by directives, water quality standards, action plans etc. and aim at assessing the environmental state and detecting trends (EEA 2011). Due to spatial and temporal variations in quality, a monitoring program, providing a representative and reliable estimation of the surface waters is necessary. Various methods can be applied to characterize and evaluate freshwater sources by interpreting complex data sets, created by long-term water quality monitoring programs (Zhang et al. 2009). Since the state of an ecosystem is dependent simultaneously on many factors and parameters, these systems are multivariate in nature (Simeonov et al. 2010). Therefore the interpretation of the monitoring data sets has to be performed by use of the multivariate statistical methods rather than univariate (Voza et al. 2015).

In the present study, a data matrix obtained from three reservoirs "Tahtalı, Balçova and Ürkmez" in Izmir, Turkey, during 4 years of monitoring program, on monthly basis, was subjected to different environmetric techniques. Overall objective of the study was a) to extract parameters that are most important in assessing variation in water quality, b) to investigate seasonal differences in water quality, c) to investigate dissimilarities between reservoirs, and d) to determine parameters discriminating water quality. In this scope the data sets were subjected to principal component analysis, Student's t-test and discriminant analysis.

\section{Study Area}

Tahtalı, Balçova and Ürkmez reservoirs provide drinking water to the city of Izmir, the third largest metropolitan area in Turkey with a population of over 3 million. Tahtalı Basin covers an area of approximately $550 \mathrm{~km}^{2}$ and the capacity of the reservoir located within the basin is 285 million $\mathrm{m}^{3}$ providing about 5 million $\mathrm{m}^{3}$ water per month. $42.1 \%$ of the basin is covered by forest, $31.8 \%$ of the area is composed of agricultural land, $0.2 \%$ of the area is industrial area and $1.8 \%$ is residential area. Balçova Reservoir is located on Ilıca River with the capacity of 7.6 million $\mathrm{m}^{3}$ and produces about 1.2 million $\mathrm{m}^{3}$ water per month to the city (as of May-August 2015). Land use structure in the Balçova Basin is as follows: forested area $-26.8 \%$, urban settlement area - 48.4\%, greenhouse agriculture $3.8 \%$, citrus-fruit orchards $11.8 \%$ and other uses (olive growth, rainfed agricultura etc.) (Bolca et al. 2007). Ürkmez Reservoir with $30.81 \mathrm{~km}^{2}$ drainage area has 8.25 million $\mathrm{m}^{3}$ water storage capacity. On average 1.5 million $\mathrm{m}^{3}$ water per month is generated from the reservoir 
(as of August-October 2015). Land use distribution in the region is $41.2 \%$ forest, $34.2 \%$ pasture, $13.7 \%$ agricultural land, $9.7 \%$ settlement and water body 1.3\% (Boyacioglu 2014, Gülersoy 2014, IZSU 2016). The location of the reservoirs is seen in Fig.1.

\section{Study method}

\section{Water quality analysis}

In the study, water quality samples were obtained from the Tahtalı, Balçova and Ürkmez reservoirs abstraction structures on a monthly basis for 4 years. Water quality samples were analyzed at the laboratory for metals and inorganic pollution parameters. In this scope iron-Fe, manganese- $\mathrm{Mn}$, copper- $\mathrm{Cu}$, zinc-Zn, fluoride-F, boron-B, arsenic-As, chromium-Cr, lead$-\mathrm{Pb}$, barium- $\mathrm{Ba}$, chloride- $\mathrm{Cl}$ and sulphate- $\mathrm{SO}_{4}$ concentrations in water samples were determined according to procedures described in Standard Methods for Examination of Water and Waste Water (APHA 2005).

\section{Statistical analysis}

In the study data sets were subjected to principal component analysis, Student's t-test and discriminant analysis.

Factor analysis was employed on the variables that are correlated to isolate or determine specific factors that are associated with such groupings of physico-chemical characteristics so as to establish their origin. It is multivariate statistical method that reduces the complexity of large data set and eliminates redundant information. The method attempts to explain the correlations between the observations in terms of the underlying factors, which are not directly observable.

There are three stages in factor analysis:

- for all the variables a correlation matrix is generated (this step is the determination of the parameter correlation matrix. It is used to account for the degree of mutually shared variability between individual pairs of water quality variables),

- factors are extracted from the correlation matrix based on the correlation coefficients of the variables (eigenvalues and factor loadings for the correlation matrix are determined. Eigenvalues correspond to an eigenfactor which identifies the groups of variables that are highly correlated among them. Lower eigenvalues may contribute little to the explanatory ability of the data. Once the correlation matrix and eigenvalues are obtained, factor loadings are used to measure the correlation between the variables and factors),

- to maximize the relationship between some of the factors and variables, the factors are rotated (factor rotation is used to facilitate interpretation by providing a simpler factor structure) (Singovszka and Balintova 2012, Gao et al. 2011).

Student's t-test is one of the most commonly used techniques for testing a hypothesis on the basis of a difference between sample means. The difference in concentrations between summer and winter seasons has been examined using Student's t test at a significant level of 0.05 .

Discriminant analysis was used to classify cases into categorical dependent values and also determine variables that discriminate between naturally occurring groups. The method constructs a discriminant function for each group given several quantitative (independent) variables and categorical (dependent) variables (Singh et al. 2004, Juahir et al. 2010). In the stepwise method, the first variable included in this analysis is the largest acceptable value for the selection criterion. The selection criterion is the minimization of Wilks lambda. Stepwise dicriminant analysis was proved to be the most

\section{B: Balcova Reservoir}

\section{U: Urkmez Reservoir}

\section{T: Tahtali Reservoir}

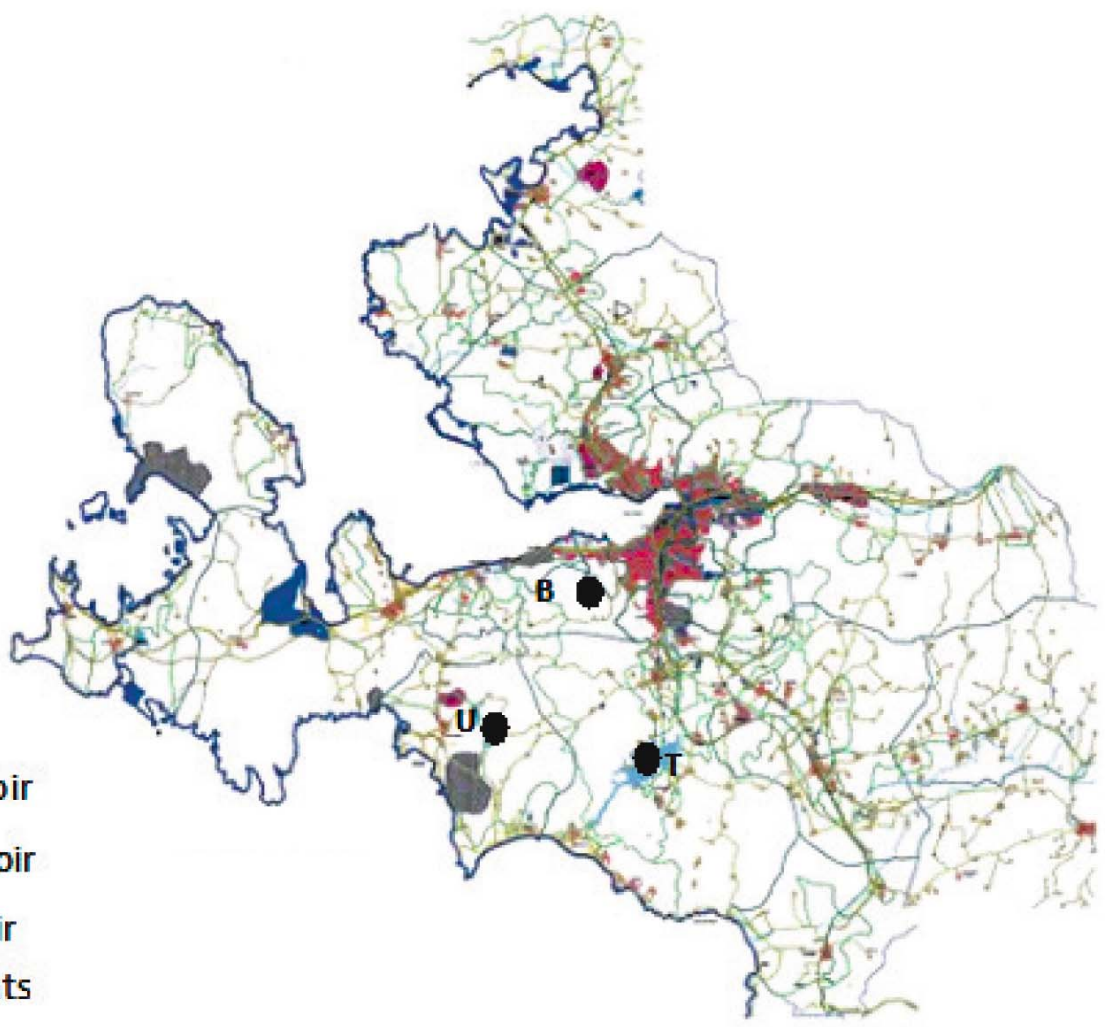

Fig. 1. Location of water reservoirs 
effective mode for reducing the dimensionality of the large dataset (Aris et al. 2013).

In the study all mathematical and statistical computations were made using SPSS Statistics (version 21).

\section{Results and discussion}

\section{Investigation of natural \& antropogenic controls and variations (spatial \& temporal)}

Descriptive statistics (mean, median, standard deviation, skewness, minimum and maximum) of water quality data sets belonging to three reservoirs are presented in Table 1. In order to avoid the influence of occasional extreme pollution events during the period of study, outliers were screened by using box plots.

Factor analysis was used to identify the key variables with the highest influence on water quality characteristics. It was applied to standardized data set (through z-scale transformation) to avoid misclassifications arising from the different orders of magnitude of both numerical values and variance of the parameters analyzed. The correlation matrix of variables representing three reservoirs water quality was generated and factors extracted by the Centroid method, rotated by Varimax rotation for the data set. Calculated eigenvalues, percent total variance, factor loadings and cumulative variances are given through Tables $2-4$. In the study positively correleted variables with each factor and occurance of which in surface waters were the basis to determine most important parameters in assessing variation in water quality.

The difference in concentrations between summer (June-July-August) and winter seasons (December-January-February) has also been examined using Student's t-test at 0.05 significance level. Mean and p values (results of the-test) of variables are shown in Table 5.

Each reservoir data set was evaluated individually in the following sections.

\section{Tahtalı Reservoir}

The factor analysis generated four significant factors for Tahtali Reservoir. The factors and positively correlated variables with these factors are:

- Factor 1 (F1): B, As, F

- Factor 2 (F2): $\mathrm{Cr}, \mathrm{Cu}$

- Factor 3 (F3): Ba, Mn

- Factor 4 (F4): Zn

Four principal factors were identified as responsible for the data structure explaining $80 \%$ of the total variance (Table 1 ). F1 was positively correlated with "B, As, F" and F2 had a high positive loading on " $\mathrm{Cr}$ and $\mathrm{Cu}$ ". $\mathrm{F} 1$ and $\mathrm{F} 2$ explained $\approx 51 \%$ of the total variance ( $\approx 27 \%$ for $\mathrm{F} 1$ and $\approx 24 \%$ for $\mathrm{F} 2$ ).

Table 1. Descriptive statistics of Tahtali. Balcova and Urkmez Reservoirs (in mg/l)

\begin{tabular}{|c|c|c|c|c|c|c|c|c|c|c|c|c|}
\hline & $\mathrm{Fe}$ & Mn & $\mathrm{Cu}$ & Zn & $\mathbf{F}$ & B & As & $\mathrm{Cr}$ & $\mathrm{Pb}$ & $\mathrm{Ba}$ & $\mathrm{Cl}$ & $\mathrm{SO}_{4}$ \\
\hline \multicolumn{13}{|c|}{ Tahtalı Reservoir } \\
\hline Mean & 0.06674 & 0.03311 & 0.00102 & 0.00811 & 0.16 & 0.05029 & 0.00408 & 0.00044 & 0.00042 & 0.02521 & 20 & 22 \\
\hline Median & 0.05435 & 0.02274 & 0.00088 & 0.00717 & 0.13 & 0.05017 & 0.00384 & 0.00036 & 0.00042 & 0.02502 & 20 & 22 \\
\hline Std. Deviation & 0.03544 & 0.02775 & 0.00059 & 0.00504 & 0.10 & 0.00558 & 0.00108 & 0.00026 & 0.00023 & 0.00474 & 1 & 5 \\
\hline Skewness & 1.36 & 1.43 & 0.83 & 1.62 & 0.61 & -1.59 & 0.54 & 1.02 & 0.59 & -0.11 & 0.22 & -0.15 \\
\hline Minimum & 0.01640 & 0.00540 & 0.00020 & 0.00210 & 0.00 & 0.02700 & 0.00260 & 0.00010 & 0.00000 & 0.01120 & 17 & 10 \\
\hline Maximum & 0.18650 & 0.11966 & 0.00250 & 0.02750 & 0.46 & 0.05960 & 0.00660 & 0.00110 & 0.00100 & 0.03700 & 23 & 34 \\
\hline \multicolumn{13}{|c|}{ Balçova Reservoir } \\
\hline Mean & 0.08204 & 0.08836 & 0.00099 & 0.01152 & 0.18 & 0.01860 & 0.00110 & 0.00062 & 0.00039 & 0.01838 & 16 & 28 \\
\hline Median & 0.06736 & 0.03659 & 0.00096 & 0.00855 & 0.15 & 0.01786 & 0.00097 & 0.00058 & 0.00035 & 0.01832 & 16 & 29 \\
\hline Std. Deviation & 0.03925 & 0.10366 & 0.00042 & 0.00778 & 0.10 & 0.00438 & 0.00042 & 0.00020 & 0.00018 & 0.00208 & 2 & 5 \\
\hline Skewness & 0.88 & 1.53 & 0.44 & 1.67 & 0.85 & 0.78 & 1.29 & 0.23 & 0.56 & 0.07 & 0.37 & -0.30 \\
\hline Minimum & 0.03030 & 0.00570 & 0.00010 & 0.00200 & 0.01 & 0.01110 & 0.00050 & 0.00020 & 0.00010 & 0.01350 & 13 & 15 \\
\hline Maximum & 0.18400 & 0.37740 & 0.00200 & 0.03630 & 0.48 & 0.02940 & 0.00240 & 0.00090 & 0.00080 & 0.02270 & 20 & 37 \\
\hline \multicolumn{13}{|l|}{ Urkmez Basin } \\
\hline Mean & 0.22710 & 0.10312 & 0.00132 & 0.00450 & 0.16 & 0.04089 & 0.00268 & 0.00125 & 0.00049 & 0.02429 & 19 & 21 \\
\hline Median & 0.18261 & 0.03479 & 0.00123 & 0.00407 & 0.15 & 0.03989 & 0.00264 & 0.00118 & 0.00047 & 0.02443 & 19 & 21 \\
\hline Std. Deviation & 0.18794 & 0.12416 & 0.00063 & 0.00247 & 0.08 & 0.00841 & 0.00090 & 0.00083 & 0.00023 & 0.00476 & 2 & 7 \\
\hline Skewness & 1.15 & 1.32 & 1.72 & 0.51 & 0.96 & 0.62 & 0.01 & 0.85 & 0.37 & 1.43 & 0.32 & 0.00 \\
\hline Minimum & 0.01600 & 0.00280 & 0.00020 & 0.00020 & 0.03 & 0.02720 & 0.00030 & 0.00020 & 0.00010 & 0.01500 & 16 & 10 \\
\hline Maximum & 0.76930 & 0.38950 & 0.00370 & 0.01020 & 0.42 & 0.06520 & 0.00500 & 0.00340 & 0.00100 & 0.04340 & 24 & 34 \\
\hline
\end{tabular}


Table 2. Factor loading matrix and total variance explained (Tahtali Reservoir)

\begin{tabular}{|l|l|l|l|l|}
\hline \multirow{2}{*}{ Tahtali Reservoir } & \multicolumn{4}{|c|}{ Factor } \\
\cline { 2 - 5 } & \multicolumn{1}{|c|}{$\mathrm{F} 1$} & \multicolumn{1}{|c|}{$\mathrm{F} 2$} & \multicolumn{1}{|c|}{$\mathrm{F} 3$} & \multicolumn{1}{|c|}{ 44 } \\
\hline $\mathrm{B}$ & .855 & -.091 & -.017 & .135 \\
\hline $\mathrm{As}$ & .845 & -.040 & -.393 & .043 \\
\hline $\mathrm{Pb}$ & -.745 & -.103 & .077 & .181 \\
\hline $\mathrm{Fe}$ & -.635 & .528 & -.090 & .392 \\
\hline $\mathrm{F}$ & .603 & -.284 & .336 & .411 \\
\hline $\mathrm{Cr}$ & -.203 & .905 & .233 & .205 \\
\hline $\mathrm{Cu}$ & .141 & .877 & -.082 & -.101 \\
\hline $\mathrm{Cl}$ & .099 & -.836 & .202 & .156 \\
\hline $\mathrm{SO}{ }_{4}$ & .125 & .111 & -.858 & -.047 \\
\hline $\mathrm{Ba}$ & -.416 & -.192 & .717 & .061 \\
\hline $\mathrm{Mn}$ & .395 & .362 & .704 & -.124 \\
\hline $\mathrm{Zn}$ & -.002 & -.021 & -.007 & .964 \\
\hline Eigen value & 3.18 & 2.85 & 2.13 & 1.40 \\
\hline$\%$ total variance & 26.52 & 23.73 & 17.75 & 11.68 \\
\hline Cumulative \% & 26.52 & 50.25 & 68.00 & 79.69 \\
\hline
\end{tabular}

Table 3. Factor loading matrix and total variance explained (Balcova Reservoir)

\begin{tabular}{|l|l|l|l|l|l|}
\hline \multirow{2}{*}{ Balcova Basin } & \multicolumn{5}{|c|}{ Factor } \\
\cline { 2 - 6 } & $\mathrm{F} 1$ & $\mathrm{~F} 2$ & $\mathrm{~F} 3$ & $\mathrm{~F} 4$ & $\mathrm{~F} 5$ \\
\hline $\mathrm{Cr}$ & .866 & .031 & .018 & .054 & .147 \\
\hline $\mathrm{Fe}$ & .785 & .185 & .012 & .210 & .356 \\
\hline $\mathrm{B}$ & .693 & .544 & -.044 & -.202 & -.258 \\
\hline $\mathrm{Mn}$ & -.536 & .359 & -.513 & .247 & .308 \\
\hline $\mathrm{As}$ & .016 & .879 & .200 & -.182 & .192 \\
\hline $\mathrm{Cu}$ & .171 & .691 & -.185 & .242 & -.025 \\
\hline $\mathrm{SO}_{4}$ & .089 & .594 & .116 & -.590 & -.072 \\
\hline $\mathrm{F}$ & .090 & .255 & .820 & .082 & .186 \\
\hline $\mathrm{Pb}$ & -.070 & .169 & -.778 & .146 & .171 \\
\hline $\mathrm{Zn}$ & -.328 & .064 & .677 & .408 & -.186 \\
\hline $\mathrm{Ba}$ & .129 & .022 & .076 & .943 & .011 \\
\hline $\mathrm{Cl}$ & .195 & .036 & -.096 & -.005 & .924 \\
\hline Eigen value & 2.35 & 2.16 & 2.11 & 1.67 & 1.30 \\
\hline$\%$ total variance & 19.56 & 18.01 & 17.55 & 13.93 & 10.87 \\
\hline Cumulative \% & 19.56 & 37.57 & 55.12 & 69.05 & 79.91 \\
\hline
\end{tabular}

Table 4. Factor loading matrix and total variance explained (Urkmez Reservoir)

\begin{tabular}{|l|l|l|l|l|l|}
\hline \multirow{2}{*}{\multicolumn{1}{c|}{ Ürkmez Basin }} & \multicolumn{5}{|c|}{ Factor } \\
\cline { 2 - 6 } & \multicolumn{1}{|c|}{$\mathrm{F} 1$} & \multicolumn{1}{|c|}{$\mathrm{F} 2$} & \multicolumn{1}{c|}{$\mathrm{F} 3$} & \multicolumn{1}{c|}{$\mathrm{F} 4$} & \multicolumn{1}{c|}{ F5 } \\
\hline $\mathrm{Fe}$ & .893 & .104 & -.132 & -.172 & .207 \\
\hline $\mathrm{Cr}$ & .845 & .343 & .200 & -.141 & .199 \\
\hline $\mathrm{Cu}$ & .755 & -.301 & .079 & .108 & -.268 \\
\hline $\mathrm{B}$ & -.620 & .430 & -.028 & .321 & -.437 \\
\hline $\mathrm{As}$ & .075 & .875 & .191 & .153 & .039 \\
\hline $\mathrm{Zn}$ & .025 & -.872 & -.136 & .338 & -.066 \\
\hline $\mathrm{Cl}$ & .081 & .031 & .922 & .077 & .114 \\
\hline $\mathrm{Ba}$ & -.152 & .533 & .783 & .015 & -.123 \\
\hline $\mathrm{F}$ & -.077 & .037 & .160 & .945 & .037 \\
\hline $\mathrm{SO}{ }_{4}$ & -.295 & -.289 & -.533 & .643 & -.265 \\
\hline $\mathrm{Mn}$ & .087 & .022 & .045 & .016 & .971 \\
\hline $\mathrm{Pb}$ & .194 & .241 & .496 & -.490 & .538 \\
\hline Eigen value & 2.64 & 2.36 & 2.14 & 1.86 & 1.68 \\
\hline$\%$ total variance & 21.99 & 19.66 & 17.85 & 15.46 & 14.02 \\
\hline Cumulative \% & 21.99 & 41.65 & 59.50 & 74.96 & 88.99 \\
\hline
\end{tabular}

\section{Fingerprinting of pollution}

Inorganic contamination of aquatic environment is caused by naturally occuring substances (fluoride, arsenic and boron), industrial waste (mercury, cadmium, chromium, cyanide and others), agricultural and domestic waste (nitrogen compounds) (UNESCO 2010). Due to the extensive occurrence of clay-rich sedimentary rocks on the Earth's land surfaces, the majority of boron mobilized into soils and the aquatic environment by weathering probably stems from this source. Natural weathering is estimated to release more boron into the environment than industrial sources (CCME 2009). Boron concentrations in fresh surface water range from $<0.001$ to $2 \mathrm{mg} / \mathrm{l}$ in Europe, with mean values typically below $0.6 \mathrm{mg} / \mathrm{l}$. Similar concentration ranges have been reported for water bodies within Pakistan, Russia and Turkey, from 0.01 to $7 \mathrm{mg} / \mathrm{l}$, with most values below $0.5 \mathrm{mg} / 1$ (WHO 2003a). Arsenic is commonly found in natural waters and its concentration depends on type of geological environment and degree of pollution in a given area. The natural concentration can vary from decimal correspondence to tens of $\mu \mathrm{g} / \mathrm{ml}$ (Niedzielski 
et al. 2002). However, in areas with volcanic rock and sulfide mineral deposits in areas containing natural sources, levels as high as $12 \mathrm{mg} / \mathrm{l}$ have been reported near anthropogenic sources (e.g mining and agrochemical manufacture) (WHO 2011). Fluorides are released into the environment naturally through the weathering and dissolution of minerals, in emissions from volcanoes and in marine aerosols. They are also released into the environment via coal combustion and process waters and waste from various industrial processes. The use of fluoride containing pesticides as well as the controlled fluoridation of drinking-water supplies also contribute to the release of fluoride from anthropogenic sources. Fluoride levels in surface waters vary according to location and proximity to emission sources. Surface water concentrations generally range from 0.01 to $0.3 \mathrm{mg} / \mathrm{l}$ (WHO 2002).

Based on a) these statements, b) components of first factor $\mathrm{F} 1$ - B, As, Pb c) level of concentrations presented in Table 1 , and also d) antropogenic activities in the region, it can be concluded that Tahtali Reservoir water quality is mainly governed by "natural factors".

Moreover, F2 comprised $\mathrm{Cr}$ and $\mathrm{Cu}$ and explained 24\% of the total variance. Chromium is widely distributed in the Earth's crust. The natural total content of surface waters is approximately $0.5-2 \mu \mathrm{g} / \mathrm{l}$ and the dissolved content is $0.02-0.3 \mu \mathrm{g} / \mathrm{l}$. Most surface waters contain between 1 and $10 \mu \mathrm{g}$ of chromium per litre (WHO 2003b). Copper is an abundant trace element that occurs naturally in the Earth's crust and surface waters. It can be found as a pure metal in nature and has a high thermal and electrical conductivity. Copper compounds are generally found as copper (II) salts. (USEPA 2007). Urban stormwater runoff represents an important source of heavy metals to receiving surface waters. The primary source of many metals in urban runoff is vehicle traffic. Concentrations of copper, lead and cadmium appear to be directly correlated to traffic intensity on surfaces such as highways, streets and parking lots (Prestes et al. 2006).

Considering the level of concentrations for both variables in summer and winter seasons, it cannot be argued that these are indicators of urban runoff effect. Therefore similar to F1, this grup-F2 can also be the representation of "natural effects" rather than urbanisation on water quality.

Furthermore, results of the Student's t-test given in Table 5 showed that among factor components of F1 and F2, only difference in "Arsenic" concentrations was statistically significant between summer and winter periods ( $\mathrm{P}$ value was 0 ). Mean values were 0.0035 in winter and 0.0051 in summer. This has been attributed to dilution from runoff at times of high flow (winter season) in the region.

\section{Balçova Reservoir}

Factor analysis results perfomed for Balçova Reservoir water quality data set produced the following factors. Positively correlated variables with these factors are:

- Factor 1 (F1): Cr, Fe, B

- Factor 2 (F2): As, Cu, $\mathrm{SO}_{4}$

- Factor 3 (F3): F, Zn

- Factor 4 (F4): Ba

- Factor 5 (F5): $\mathrm{Cl}$

$\mathrm{Cr}, \mathrm{Fe}$ and $\mathrm{B}$ marked $\mathrm{F} 1$ and explained $20 \%$ of the total variance (with factor loadings $0.87,0.79$ and 0.69 , respectively). The $\mathrm{F} 2$ had a high positive loading on $\mathrm{As}, \mathrm{Cu}$, $\mathrm{SO}_{4}$ (with factor loadings 0.88. 0.69 and 0.59) and explained $18 \%$ of the total variance.

\section{Fingerprinting of pollution}

Natural occurrence of chromium, boron, arsenic and copper in surface waters has already been explained previously. Moreover, iron is the second most abundant metal in the Earth's crust of which it accounts for about 5\% (WHO 2003c). Sulphates are discharged into the aquatic environment in wastes from industries that use sulphates and sulphuric acid. Acid rock drainage is also a significant source of sulphate generation. Sulphate fertilizers are also a major source of sulphate to ambient waters (BCME 2000).

Considering a) first two factor components- "Cr, Fe, B, As, $\mathrm{Cu}$ and $\mathrm{SO}_{4}$ ", b) level of concentrations of these variables

Table 5. Mean concentrations and results of Student's $t$ tests

\begin{tabular}{|c|c|c|c|c|c|c|c|c|c|}
\hline \multirow{3}{*}{ Variable } & \multicolumn{9}{|c|}{ Reservoir } \\
\hline & \multicolumn{3}{|c|}{ Tahtalı } & \multicolumn{3}{|c|}{ Balçova } & \multicolumn{3}{|c|}{ Ürkmez } \\
\hline & Winter & Summer & $P$ & winter & summer & $P$ & winter & summer & $P$ \\
\hline $\mathrm{Fe}$ & 0.0838 & 0.0549 & 0.024 & 0.0954 & 0.064 & 0.019 & 0.1939 & 0.2434 & $>0.05$ \\
\hline $\mathrm{Mn}$ & 0.0197 & 0.0483 & 0.011 & 0.0618 & 0.1143 & $>0.05$ & 0.0266 & 0.1981 & 0.000 \\
\hline $\mathrm{Cu}$ & 0.001 & 0.0012 & $>0.05$ & 0.0012 & 0.0009 & $>0.05$ & 0.0013 & 0.0011 & $>0.05$ \\
\hline $\mathrm{Zn}$ & 0.0078 & 0.0098 & $>0.05$ & 0.0087 & 0.0125 & $>0.05$ & 0.004 & 0.0045 & $>0.05$ \\
\hline $\mathrm{F}$ & 0.14 & 0.18 & $>0.05$ & 0.15 & 0.18 & $>0.05$ & 0.17 & 0.17 & $>0.05$ \\
\hline$B$ & 0.0498 & 0.053 & $>0.05$ & 0.0193 & 0.0196 & $>0.05$ & 0.0459 & 0.0374 & 0.011 \\
\hline As & 0.0035 & 0.0051 & 0.000 & 0.0011 & 0.0012 & $>0.05$ & 0.0031 & 0.0022 & 0.000 \\
\hline $\mathrm{Cr}$ & 0.0005 & 0.0003 & $>0.05$ & 0.0007 & 0.0005 & $>0.05$ & 0.0013 & 0.0013 & $>0.05$ \\
\hline $\mathrm{Pb}$ & 0.0004 & 0.0004 & $>0.05$ & 0.0004 & 0.0004 & $>0.05$ & 0.0004 & 0.0005 & $>0.05$ \\
\hline $\mathrm{Ba}$ & 0.0255 & 0.024 & $>0.05$ & 0.0171 & 0.0191 & 0.032 & 0.0253 & 0.0232 & $>0.05$ \\
\hline $\mathrm{Cl}$ & 20 & 20 & $>0.05$ & 17 & 16 & $>0.05$ & 20 & 18 & 0.034 \\
\hline $\mathrm{SO}_{4}$ & 24 & 21 & $>0.05$ & 30 & 28 & $>0.05$ & 25 & 19 & 0.007 \\
\hline
\end{tabular}


presented in Table 1, and c) source of these substances in water, it can be concluded that Balçova reservoir water quality is mainly controlled by "natural factors".

Furthermore, among components of the first two factors (F1 and F2), difference in iron concentrations in summer and winter periods was statistically significant ( $p$ value was 0.019 ). Higher mean values were observed in winter $(0.083 \mathrm{mg} / \mathrm{L})$ and lower in summer $(0.055 \mathrm{mg} / \mathrm{L})$. Higher iron levels in winter could be explained by seepage through soil and enterance to the river with the rainwater run-off process (Kaur and Mehra 2012).

\section{Ürkmez Reservoir}

Factor analysis results performed for Ürkmez Reservoir water quality data set generated five factors explaining $89 \%$ of the total variance. Positively correlated variables with these factors are:

- Factor 1 (F1): $\mathrm{Fe}, \mathrm{Cr}, \mathrm{Cu}$

- Factor 2 (F2): As

- Factor 3 (F3): Cl, Ba

- Factor 4 (F4): F, $\mathrm{SO}_{4}$

- Factor 5 (F5): $\mathrm{Mn}, \mathrm{Pb}$

F1 was positively correlated with " $\mathrm{Fe}, \mathrm{Cr}, \mathrm{Cu}$ " and F2 with "As". Factor loadings were 0.90, 0.85, 0.76 and 0.88 , respectively. Quality of water showed quite similar characteristics to Balçova reservoir with the presence of similar factor components explaining higher percentage of variance in data set.

\section{Fingerprinting of pollution}

Considering a) natural occurance factor components that has ben explained in the previous sections and b) level of concentrations, it can also be concluded that Ürkmez reservoir water quality was mainly controlled by "natural factors". Among the factor components of F1 and F2, difference in arsenic concentrations in summer and winter periods was statistically significant. Lower levels have been observed in summer months (Table 5). This implies that adsorption processs is more important in attenuating arsenic concentrations during periods of dry weather in the region (Gault et al. 2003).

\section{Investigation of dissimilarities between reservoirs}

In the study discriminant analysis was performed on the original data based on the stepwise mode to construct the best discriminant functions. Discriminant functions with small Wilk's Lambda and a large chi-square respectively $(\mathrm{p}<0.05)$ indicated that the spatial discriminant analysis was credible and effective (Table 6). In other words the discriminant functions were sufficient to explain the difference of water quality among reservoirs. Classification functions obtained from analysis are shown in Table 7. The stepwise method identified "boron, arsenic and sulphate" as the most important variables discriminating Balçova \& Tahtalı and Balçova \& Ürkmez reservoirs (Table 7). As is presented in Table 5, boron and arsenic levels were considerably lower and sulphate was higher in the Balcova reservoir compared to the others. On the other hand, "zinc and arsenic" were the discriminating variables between Tahtalı \& Ürkmez reservoirs. The levels of both variables were higher in the Tahtalı reservoir.

\section{Conclusion}

In the study, environmetric methods were used to investigate a) natural and anthropogenic controls of water quality and b) seasonal \& spatial variations in water quality of three reservoirs in Izmir, Turkey. Factor analysis helped to identify the factors/sources responsible for variations in reservoir water quality at three different sites. The method produced four factors in the Tahtalı, five factors in the Balçova and Ürkmez Reservoirs. For each data set a) positively correleted variables with first two factors, b) occurance of these variables in surface waters, and c) levels in the reservoirs were the basis to fingerprint pollution. Results indicated that water quality in three resorvoirs was mainly governed by "natural factors"

Table 6. Wilk's lamda and chi-square test for the discriminant analysis of spatial variation in water quality

\begin{tabular}{|l|c|c|c|c|c|}
\hline \multicolumn{1}{|c|}{ Reservoir } & $\mathrm{R}$ & Eigenvalue & $\begin{array}{c}\text { Wilks' } \\
\text { Lambda }\end{array}$ & chi-square & p-level \\
\hline Balcova\&Tahtali & 0.94 & 14.917 & 0.063 & 84.405 & 0.00 \\
\hline Balcova \& Ürkmez & 0.88 & 7.461 & 0.118 & 67.268 & 0.00 \\
\hline Tahtalı \& Ürkmez & 0.61 & 1.597 & 0.385 & 28.639 & 0.00 \\
\hline
\end{tabular}

Table 7. Classification function coefficients for the discriminant analysis (DA) of Table 6

\begin{tabular}{|c|c|c|c|c|c|}
\hline \multicolumn{2}{|c|}{ Balcova\&Tahtalı } & \multicolumn{2}{c|}{ Balcova\&Urkmez } & \multicolumn{2}{c|}{ Tahtalı\&Ürkmez } \\
\hline Parameters & Function & Parameters & Function & Parameters & Function \\
\hline B & 8.136 & B & 8.744 & Zn & 3.025 \\
$\mathrm{As}$ & 5.474 & $\mathrm{As}$ & 3.534 & As & 9.771 \\
$\mathrm{SO}_{4}$ & -9.699 & $\mathrm{SO}_{4}$ & -4.974 & & \\
\hline (Constant) & 41.094 & (Constant) & 30.485 & (Constant) & 31.556 \\
\hline
\end{tabular}


rather than antropogenic sources. Furthermore, the results of the Student's t-test showed that among the first two factor components difference in "arsenic" concentrations between summer and winter periods was statistically significant in Tahtalı reservoir. Lower levels in winter season were explained by dilution from runoff at times of high flow. Similar to the Tahtalı reservoir, "arsenic" was the variable having difference between two seasons in Ürkmez reservoir. Here the main difference was that lower levels have been observed in summer months. This implied that adsorption process was more important in attenuating arsenic concentrations during the periods of dry weather in the region. In contrast, in the Balcova reservoir iron levels showed seasonal differences. Higher iron levels in winter could be explained by seepage through soil and enterance to the river with the rainwater run-off process Furthermore, discriminant analysis gave the best results to investigate spatial differences. For three reservoirs it yielded an important data reduction. It used only three parameters "boron, arsenic, sulphate" to discriminate quality between Balcova \& Tahtalı and Balcova \& Ürkmez reservoirs and two parameters "zinc and arsenic" between Tahtalı \& Ürkmez reservoirs. Therefore the method allowed for a reduction in the dimensionality of the large data set delineating a few indicator parameters responsible for large variations in water quality. This study illustrated the effectiveness of multivariate statistical techniques to investigate natural \& anthropogenic controls of seasonal and spatial variations in water quality.

\section{References}

APHAAmerican Public Health Association (2005). Standard methods for the examination of water and waste water. 21st edition, American Public Health Association, Washington 2005.

Aris, A.Z., Praveena, S.M., Isa, N.M., Lim, W.Y., Juahir, H., Yusoff, M.K. \& Mustapha, A. (2013). Application of environmetric methods to surface water quality assessment of Langkawi Geopark (Malaysia), Environmental Forensics, 14:3, pp. 230-239.

BCME-British Columbia Ministry of Environment-Lands and Parks (2000). Ambient water quality guidelines for sulphate. Water quality. ambient water quality guidelines for sulphate overview report.

Bolca, M., Turkyılmaz, B., Kurucu, Y., Altınbaş, Ü., Esetlili, M.T. \& Gülgün, B. (2007). Determination of impact of urbanization on agricultural land and wetland land use in Balçovas Delta by remote sensing and GIS technique, Environmental Monitoring and Assessment, 131, pp. 409-419.

Boyacioglu, H. (2014). Spatial differentiation of water quality between reservoirs under anthropogenic and natural factors based on statistical approach, Archives of Environmental Protection, 40/1, pp. 41-50.

CCME-Canadian Environmental Quality Guidelines (2009). Canadian Water Quality Guidelines for the Protection of Aquatic Life. Canadian Council of Ministers of the Environment.

EEA (2011): European Environment Agency. Surface water quality monitoring. Retrieved April 18, 2016 from http://www.eea. europa.eu/publications/92-9167-001-4/page003.html

Gao, C. Yan, J.. Yang, S \& Tan, G. (2011). Applying factor analysis to water quality assessment: a study case of Wenyu River. Nonlinear mathematics for uncertainty and its applications AISC 100 Chapter. pp. 541-547.
Gault, A.G., Polya, D.A. \& Lythgoe, P.R. (2003). Seasonal variation of total dissolved arsenic and arsenic speciation in a polluted surface waterway, Environmental Geochemistry and Health, 25/1, pp. $77-85$.

Gülersoy, A. (2014). Temporal change of land use in Seferihisar (1984-2010) and proposals for optimal land use. SDU Faculty of Arts and Sciences, Journal of Social Sciences, 31, pp. 155-180.

IZSU (Izmir Water Supply and Sewerage Authority). (www.izsu.gov. $\operatorname{tr}(05.05 .2016))$.

Juahir, H., Zain, S., Aris, A.Z. \& Mokhtar, L.M. (2010). Spatial assessment of Langat River water quality using chemometrics, Journal of Environmental Monitoring, 12(1), pp. 287-295.

Kaur, S. \& Mehra, P. (2012). Assessment of heavy metals in summer \& winter seasons in River Yamuna segment flowing through Delhi, India, Journal of Environment and Ecology, 3/1, pp. 149-165.

Niedzielski, P., Siepak, J., Siepak, M. \& Kraska, M. (2002). Occurrence of arsenic, antimony and selenium in surface waters of Drawieński National Park, Polish Journal of Environmental Studies, 11/1, pp. 41-45.

Prestes, E.C., Anjos, V.E, Sodré, F.F. \& Grassi, M.T. (2006). Copper, lead and cadmium loads and behavior in urban stormwater runoff in Curitiba, Brazil, Journal of the Brazilian Chemical Society, 17/1. DOI: 10.1590/S0103-50532006000100008.

Simeonov, V., Simeonova, P., Tsakovski, S. \& Lovchinov, V. (2010). Lake water monitoring data assessment by multivariate statistics, Journal of Water Resource and Protection, 2, pp. 353-361.

Singh, K.P., Malik, A., Mohan, D. \& Sinha, S.(2004). Multivariate statistical techniques for the evaluation of spatial and temporal variations in water quality of Gomti River (India). A case study, Water Research, 38(18), pp. 3980-3992.

Singovszka, E. \& Balintova, M. (2012). Application factor analysis for the evaluation surface water and sediment quality, Chemical Engineering Transactions, 26, pp. 183-188.

UNESCO (2010). Water Quality and standards Editors: Kubota S. and Tsuchiya Y. EOLSS Publishers.

USEPA (2007). United States Environmental Protection Agency. Aquatic life ambient freshwater quality criteria for copper - 2007 Revision.

WHO (2002): Environmental Health Criteria 227 Fluorides.

WHO (2003a): Boron in drinking-water background document for development of WHO guidelines for drinking-water quality. $\mathrm{WHO} / \mathrm{SDE} / \mathrm{WSH} / 03.04 / 54$.

WHO (2003b): Chromium in drinking-water background document for development of WHO Guidelines for drinking water quality. Guidelines for drinking-water quality, WHO/SDE/WSH/03.04/04. World Health Organization, Geneva.

WHO (2003c): Iron in drinking-water background document for development of who guidelines for drinking-water quality. $\mathrm{WHO} / \mathrm{SDE} / \mathrm{WSH} / 03.04 / 08$.

WHO (2011): Arsenic in drinking-water background document for development of WHO guidelines for drinking-water quality. WHO/SDE/WSH/03.04/75/Rev/1.

Voza, D., Vukovic, M., Takic, L., Nikolic, D. \& Ranisavljevic, I.M. (2015). Application of multivariate statistical techniques in the water quality assessment of Danube river, Serbia, Archives of Environmental Protection, 41/4, pp. 96-103.

Zhang, Q., Li, Z., Zeng, G., Li, J., Fang, Y., Yuan, Q., Wang, Y. \& Ye, F. (2009): Assessment of surface water quality using multivariate statistical techniques in red soil hilly region: A case study of Xiangjiang Watershed, China, Environmental Monitoring and Assessment, 152, pp. 123-131. 